\title{
Individual EEG alpha-indices and nonverbal creativity in female during the spontaneous menstrual cycle in comparison with male subjects
}

\author{
Olga Bazanova*1 and Lubomir Aftanas ${ }^{2}$
}

Address: ${ }^{1}$ State-Research Institute of Moleullar Biology and Biophysics, Siberian Branch, Russian Academy of Medical Sciences, Novosibirsk, Russia and ${ }^{2}$ State-Research Institute of Physiology, Siberian Branch, Russian Academy of Medical Sciences, Novosibirsk, Russia

* Corresponding author

from International Society on Brain and Behaviour: 3rd International Congress on Brain and Behaviour

Thessaloniki, Greece. 28 November - 2 December 2007

Published: 17 April 2008

Annals of General Psychiatry 2008, 7(Suppl I):SI0I doi:I0.I I86/I744-859X-7-SI-SIOI

This abstract is available from: http://www.annals-general-psychiatry.com/content/7/SI/SI0I

(c) 2008 Bazanova and Aftanas; licensee BioMed Central Ltd.

\section{Background}

A major argument for excluding females from research in psychophysiology has been the difficulty in controlling for the confounding factor of hormonal changes associated with the menstrual cycle in women [1]. It was shown that nonverbal creativity is associated with individual EEG alpha-activity indices in males [2]. The aim of this study was to investigate whether changes in nonverbal creativity are associated with changes in EEG alpha activity during the menstrual cycle in females and what is the gender effect in these associations.

\section{Materials and methods}

EEG alpha indices levels, its reactivity for opening eyes and Torrance test performance were studied in a within subject design with 30 women in comparison with 27 men. Basal body temperature was monitored daily; menstrual, follicular, ovulatory and luteal EEG recording sessions occurred before and after the ovulatory temperature rise, respectively. Scores of nonverbal creativity (i.e., fluency, originality, and flexibility) were assessed using the Torrance test of nonverbal performance. 1510 $\mathrm{Hz})>$ women and 14 men belonged to high individual alpha peak frequency (IAPF group, 14 women and 13 men - to low IAPF $(<10 \mathrm{~Hz})$ group.

\section{Results}

The results showed menstrual phase differences in EEG alpha power, IAPF, individual alpha band width and EEG reactivity to open eyes, fluency and plasticity in Torrance test performance, particularly in low IAPF group, but no difference in reactivity in high IAPF group in women. Gender effects were detected in the ovulatory and luteal stages. The study showed that fluency in creative performance was associated with IAPF in high estrogen state, whereas originality and plasticity - with individual alpha band width and reactivity to open eyes in all groups.

\section{Conclusions}

This investigation demonstrated that gender effect and the EEG alpha-activity changes in a parallel with changed baseline temperature (hormone levels) are depended on the baseline IAPF. The changes in nonverbal creativity performance coincide with increasing or decreasing individual alpha activity indices in the EEG.

\section{References}

I. Kaplan BJ, Whitsett SF, Robinson JW: Menstrual Cycle Phase is a Potential Confound in Psychophysiology Research. Psychophysiology 1990, 27:445-450.

2. Bazanova $O$, Aftanas L: Relationships between learnability and individual indices of EEG alpha activity. Annals of General Psychiatry 2006, 5:74-75. 